\title{
Pragmatic Rhetorical Principles in Isocrates
}

GERARDO RAMÍREZ VIDAL / National Autonomous Universty of México /

The aim of this paper is twofold. ${ }^{1}$ First, I am going to identify Isocrates' three rhetorical principles, i.e., opportunity (kairos), suitability (to prepon) and novelty (kainos), as three pragmatic principles within the rhetorical system of his philosophy. Next, I am going to explain the significance of opportunity and suitability, and discuss what Isocrates means by these terms. Prior to that, it is necessary to present the following premises.

1. Isocrates never employed the word "rhetoric" to refer to his educational activity. He made frequently use of the expression "philosophia of the words", although he also employed other terms in lieu of philosophia: education (paideia), practice (meletē) or dedication (epimeleia).

2. The word "rhetoric" signified just the "art of the rhètor", and rhètor was a public orator, that is to say, a politician who spoke before the assembly or before the board of judges.

${ }^{1}$ I am indebted to Debbie Sivertson, who reviewed the original text.

${ }^{2}$ Isocrates uses rhètoreia ('oratory', 'oration') and rhētoreuein ('to be an orator'), cf. Schiappa 1999: 158-159. 
3. Plato labeled Isocrates' profession as "rhetoric" so as to belittle the meaning and the field of his teaching. For Isocrates, the word "philosophy" did not signify "unselfish love for the truth" or anything of that sort, since this definition of the word was introduced only by Plato. For Isocrates, philosophy meant simply "skill" or "ability", ${ }^{3}$ and his philosophy of rhetoric stood for the teaching-learning of speech ability. Consequently, whenever I use the phrase "Isocrates' rhetoric", I refer to Isocrates' philosophy of rhetoric (i.e. rhetorical skill).

\section{The nature, teaching and practice of rhetoric}

In his Antidosis, Isocrates says very clearly that to become a great orator, one needs three

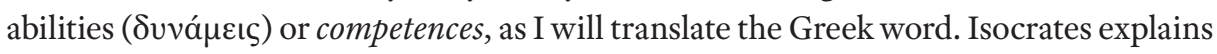
it in the following fundamental passage of the Antidosis (15.187):

I say to them that if they are to excel in oratory or in managing affairs or in any line of work, they must, first of all, have a natural aptitude for that which they have elected to do; secondly, they must submit to training and master the knowledge of their particular subject, whatever it may be in each case; and, finally, they must become versed and practiced in the use and application of their art; for only on these conditions can they become fully competent and pre-eminent in any line of endeavor (Norlin's translation).

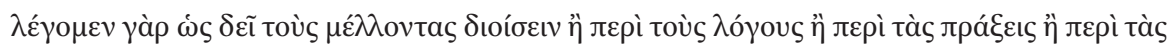

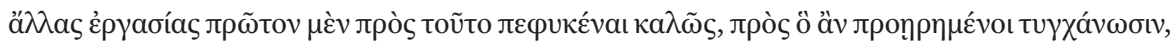

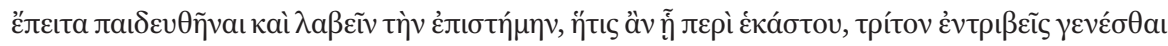

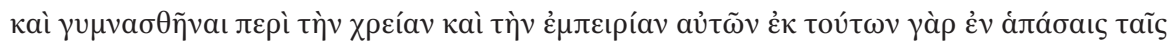

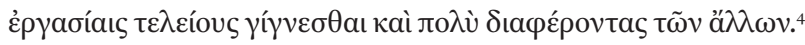

Thus, the first necessary condition is having a natural predisposition for oratory. I shall call it oratory competence. The second condition is carrying out an apt teaching-learning process. I shall call it rhetoric competence. Finally, the third condition is about the practice, which consists in applying the theory to various actual cases. I shall call it pragmatic competence. Rhetorical philosophy (or skill) is oriented to these three necessary and interrelated capacities or competences. We can illustrate the concept of pragmatic competence by the following tentative table (the shaded part will be the focus of the present paper):

3 Pace Schiappa 1999: 168-184. We can understand Philosophy as a "political ability" (see Ramírez Vidal 2016: 193-194).

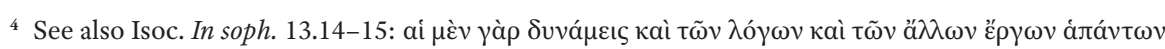

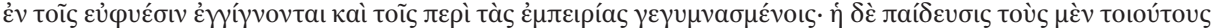

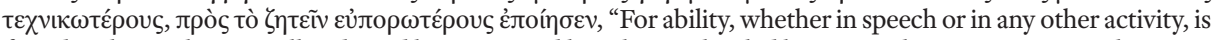
found in those who are well endowed by nature and have been schooled by practical experience. Formal training makes such men more skilfull and more resourceful in discovering the possibilities of a subject" (Norlin's trans-

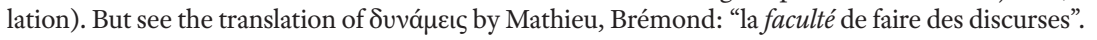


ISOCRATES' RHETORICAL PHILOSOPHY

\begin{tabular}{|c|c|c|c|}
\hline & \multicolumn{3}{|c|}{ 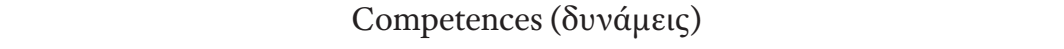 } \\
\hline & 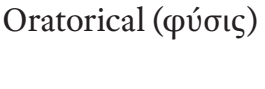 & 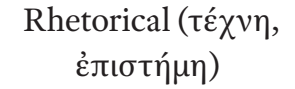 & 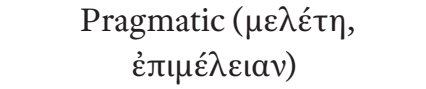 \\
\hline \multirow{3}{*}{ 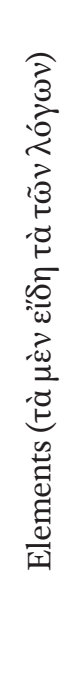 } & \multirow{3}{*}{ 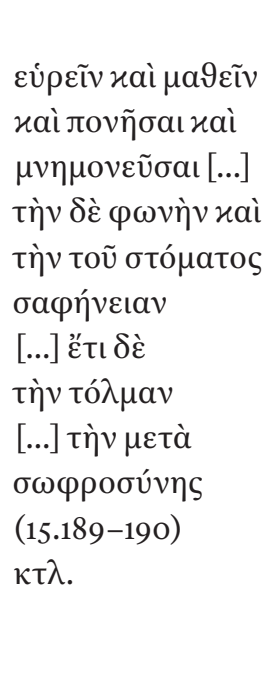 } & 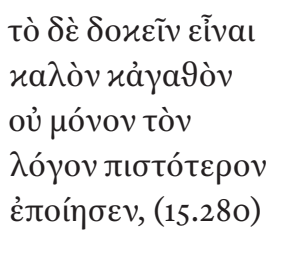 & 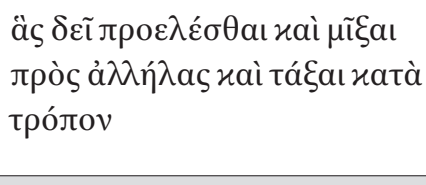 \\
\hline & & 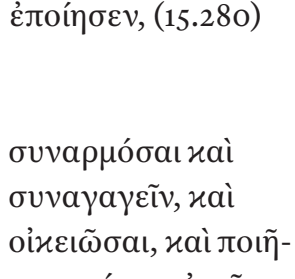 & 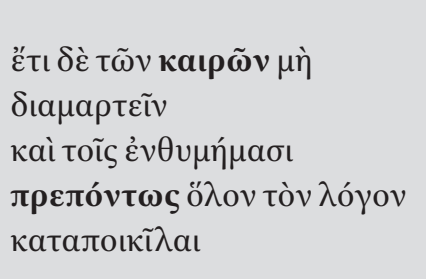 \\
\hline & & 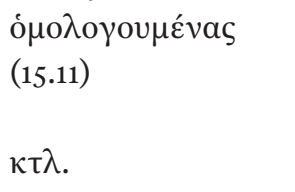 & 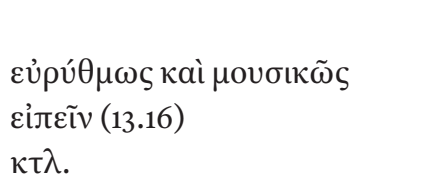 \\
\hline
\end{tabular}

Sources: Isoc. In soph. 13.16-17; Antid. 15.11.183-185; 189-190; 276-282, etc.

\section{Teaching and practice}

For Isocrates, pragmatic competence (i.e., the practice or performance of actual discourse) was an indispensable branch of training the ideal orator. According to him, the natural capacity and practice were more important than the theory. Thus, a person trained in pragmatic competence can become even better than a person that has only the natural competence but has never bothered to put it into practice. It is obvious that an outstanding orator is a person that has both competences, natural and pragmatical. ${ }^{5}$

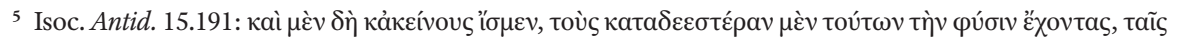

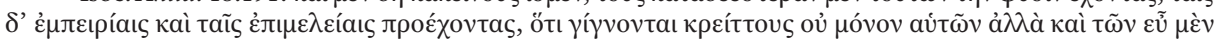

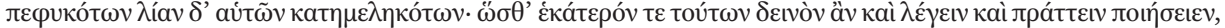

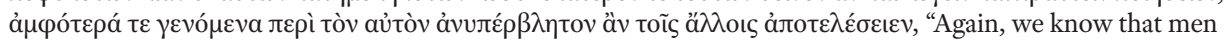


In any case, teaching rhetoric has a strong connection with its execution. The teacher's activity can modify the natural skill by practicing the knowledge obtained during the instruction in such a way that the pragmatic and rhetorical competences are, in addition to the innate capacities of a person, two aspects of the potential orator's development: "Whenever you desire to gain a thorough understanding of such things as it is fitting that kings should know, pursue them by practice as well as by study; for study will show you the way but training yourself in the actual doing of things will give you power to deal with affairs" ${ }^{6}$ The two aspects together make the learner a great orator, and in the Isocrates' school of rhetoric both aspects were taught, in such a way that practice was nothing else than exercises given by the teacher.

\section{Principles of pragmatic competence}

Nevertheless, the rhetorical theory looks at an ideal orator as someone who is in ideal circumstances and before ideal audience. Thus, the rhetorical theory is genuinely ideal and abstract, and behaves like grammatical study: it makes all circumstantial aspects equal and is focused on studying the elements contained and the connections between these. The speaker can express himself in a very clever way without theoretical knowledge of rhetoric, while the learner might still face several difficulties in skillfully applying his theoretical knowledge. In his school, Isocrates tried to solve these problems by doing exercises with observations and councils. The importance of this part of the training cannot be underestimated.

According to Isocrates' testimony (In soph. 13.12-13), the rhetoric's contemporary teachers trained their students in their doctrines as if rhetoric were a fixed technical discipline, whereas for Isocrates rhetorical philosophy was a creative activity. A fixed technique is analogous to using letters which form a word: the letters do not change and we always utilize the same ones to make reference to a same object - we cannot use the same words, though, because the issues are always different. ? We could say that speech

who are less generously endowed by nature but excel in experience and practice, not only improve upon themselves, but surpass others who, though highly gifted, have been too negligent of their talents. It follows, therefore, that either one of these factors may produce an able speaker or an able man of affairs, but both of them combined in the same person might produce a man incomparable among his fellows" (Norlin's translation).

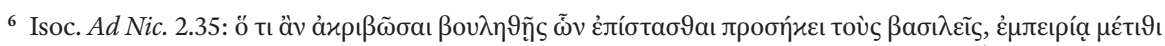

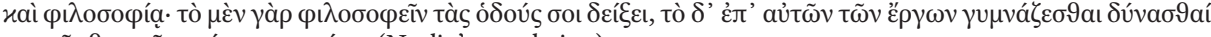

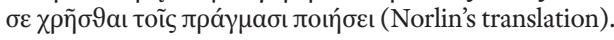

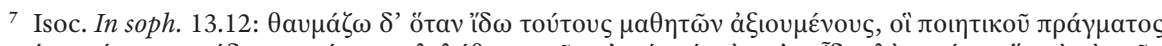

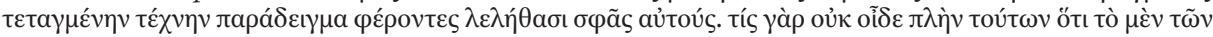

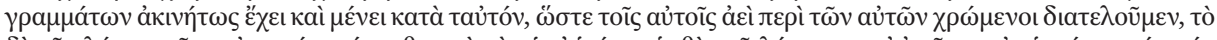

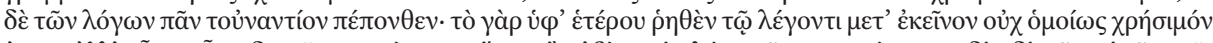

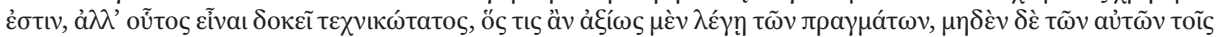

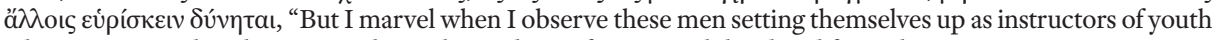
who cannot see that they are applying the analogy of an art with hard and fast rules to a creative process. For, excepting these teachers, who does not know that the art of using letters remains fixed and unchanged, so that we continually and invariably use the same letters for the same purposes, while exactly the reverse is true of the 
is exceptional, unique, distinct, diverse and singular. Then, contemporary teachers could fix the same words to be uttered by one speaker or another, as if words were letters, but this would be wrong, because what is helpful for one person is not necessarily helpful for another. ${ }^{8}$

In this way, the best art or techne consists in speaking about the issues in question appropriately, that is to say, the words have to be used in accordance with the significance of the case: the orator has to speak in conformity with the importance of the matter. The difference between letters and words lies in that, in contrast to letters, a word is correctly said, when the opportunities (kairoí), suitability or adequacy (to prepon) and novelty (to kainos) are taken into account. Hence, apart from the mere technique of speaking, i.e., apart from the sheer theoretical scheme that is to be taught and learned, the rhetor must see the use of language in a lively and practical way.

The teacher refers to a twofold language articulation. On the one hand, letters (that is to say, sounds) create words. On the other hand, words make speech. There is an important difference, though, since words are fixed, because they are employed for the same things. Speech, on the other hand, does not have this character. It is always necessary to consider the opportunities, the junctures for uttering speech; it is also necessary to adjust the word to the issue and speech in a novel way.

In the same speech (In soph. 13.16), Isocrates says that it is not difficult to know the devices which allow one to utter and compose any speech if the student is in the hands of a serious master, and not in the hands of some trickster. However, it is very difficult to learn how to apply the technical elements (eidē) to particular cases, as the elements that one has to choose, combine with each other and arrange according to the tropos or kind of issues. Furthermore, Isocrates adds, the speaker cannot make mistakes about the opportunities: it is necessary to garnish the speech with good ideas in an opportune way and to express oneself using words rhythmically and musically. The student needs to have the natural qualities and a competent teacher in order to achieve this.

Other similar passages allow us to understand the lasting importance of these theories. In the Panegyricus, the author also suggest that all orators have the possibility to use the rhetorical elements for persuading, but only the most intelligent people (Panegyr. 4.9:

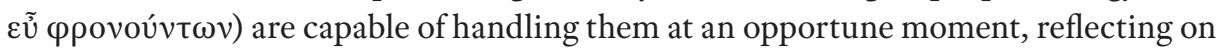
the expedients which are convenient in each particular situation and arranging them in words in a speech. ${ }^{9}$ These are the same principles of opportunity, suitability and novel-

art of discourse? For what has been said by one speaker is not equally useful for the speaker who comes after him; on the contrary, he is accounted most skilled in this art who speaks in a manner worthy of his subject and yet is able to discover in it topics which are nowise the same as those used by others" (Norlin's translation).

${ }^{8}$ Cf. Too 1995: 191: "a student will have to rivise and adapt the identity provided by his paradigm to his particular needs at any moment: he cannot take his teacher to be a rigidly prescriptive model for rhetorical action".

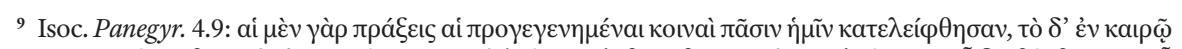

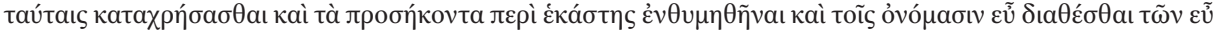

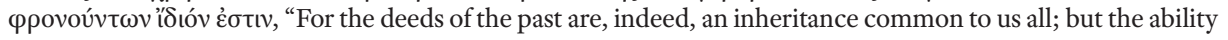


ty. In the Panathenaicus, Isocrates refuses techniques (artes), knowledge and natural gifts, and believes that the best prepared pupil is the one that can deal with issues which happen daily, the one that has an adequate opinion about the opportunities and the one that has the ability to above all appreciate utility. ${ }^{10}$ Thus, when his life came to an end, Isocrates recognized ethical issues to be more important than rhetoric itself in the strictest sense of the word. But Isocrates' teaching is rhetorical philosophy, teaching the skillful use of words related to the traditional norms, prudence and common sense.

On the basis of these passages, we realize that Isocrates considered rhetoric as a creative process, while the rules that have to be learned could not be fixed. For this reason, it is necessary for an orator to adapt his words to the issue and choose, combine and order the elements of the art according to the issue. Moreover, the same orator should pay attention to the opportunities, express himself in an adequate and novel way, and employ rhythmical and musical words.

To sum up: pragmatic competence is a perquisite for becoming an expert orator in Isocrates' rhetorical philosophy, while the fundamental principles of this theory are: a) the suitability of the rhetorical elements for the particular issue; b) the opportunity (kairos); c) the suitability of the contents (to prepon) and d) the rhythm as well as music in the expression. Each one of these principles can be seen in a specific way.

\section{Opportunity (kairos)}

Kairos or opportunity is a principle of rhetoric. ${ }^{11}$ Scientific knowledge does not have access to it. Isocrates states that "no system of knowledge can possibly cover these occasions, since in all cases they elude our science. Yet those who most apply their minds to them and are able to discern the consequences which for the most part grow out of them, will most often meet these occasions in the right way". ${ }^{12}$ Consequently, the relation of the

to make proper use of them at the appropriate time, to conceive the right sentiments about them in each instance, and to set them forth in finished phrase, is the peculiar gift of the wise" (Norlin's translation).

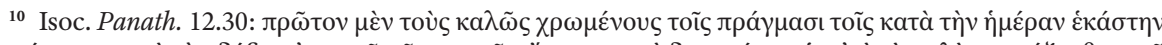

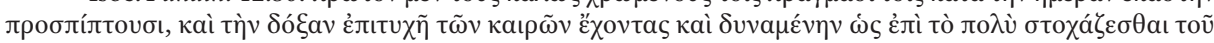

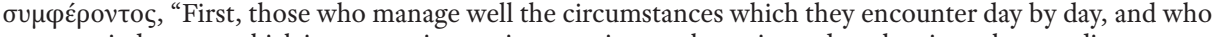
possess a judgement which is accurate in meeting occasions as they arise and rarely misses the expedient course of action" (Norlin's translation).

11 On the importance of kairós, see Sipiora, Baumlin 2002: 7-14. E.g. "What may be Isocrates' most important historical contribution, however, is his articulation of the critical importance of kairos in rhetorical theory and practice. (...) Much of Isocrates' success over nearly two millennia may be attributed to his formal system of rhetorical paideia, structured on the principle of kairos".

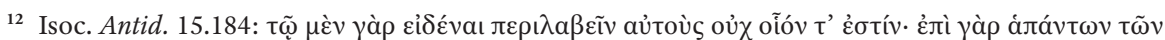

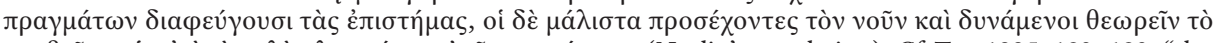

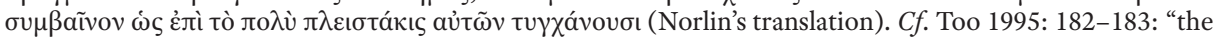
doxastic method is an empirical one: it lies in anticipating the kairoi from the indications which generally accompany them". 
suppositions or opinions (doxai) about occasions depends on the prudence or practical intelligence (phronessis) and experience, ${ }^{13}$ it is never a reliable or systematic knowledge. Although the master does not have any science for making an orator out of just any person, he can contribute in some way, and this Isocratic idea is expounded in his speeches. ${ }^{14}$

On the other hand, it is important to note that the principle of opportunity (kairos) relates not only to man's words, but to his actions as well. This is a prudential education: when to act and when to remain quiet (see Too 1995: 177). When the circumstances are unfavorable, one has wait for the opportunity to act with the intention of becoming successful every time, even if one is weak.

There are some actions that depend on the practical intelligence (phronesis), but not on the technique. We have already said that only a prudent man can profit from the past acts at opportune moment. Prudence makes one see how profitable the juncture is. Yet prudence is not an art, but rather a practice and routine. Consequently, one could think that prudence is not teachable and that opportunities cannot be learned, either. However, according to Isocrates, prudence is to be transmitted by practical advice about how to behave in different walks of life.

In Isocrates' rhetorical philosophy it is very important to choose the occasion. Indeed, the disciples do exercises on how to judge if the speech has been written according to the occasion and in an accurate style (cf. In Phil. 5.155). If a man wants to persuade, he cannot speak inaccurately, he has to speak when it is convenient and in a suitable way. This condition for a successful speech is also valid for actions. One must not wage war unless there is certainty and guarantee of success (Panegyr. 4.160). In adequate circumstances, even weak forces can tip the balance in favor of one of the armed forces in a battle (Panegyr. 4.139). Thus, actions and words are to be made at an opportune moment.

Knowledge of favorable moments is complemented with understanding of unfavorable times. Thus, eủkaı pía or "opportunity" is in opposition to ảkaıpía or "tactlessness". In his work $A d$ Dem. 1.31-32, Isocrates reflects:

[...] you must avoid being serious when the occasion is one for mirth, or taking pleasure in mirth when the occasion is serious (for what is unseasonable is always offensive); you must not bestow your favors ungraciously as do the majority who, when they must oblige their friends, do it offensively; and you must not be given to fault-finding, which is irksome, nor be censorious, which is exasperating. If possible avoid drinking-parties altogether, but if ever occasion

13 See Matson 1957: 425: "Doxa is not irresponsible guessing, but insight based on experience: worldly wisdom, which education can develop where native wit is not lacking”. Sipiora, Baumlin 2002: 9: "Phronesis, coupled with kairos, is integral to effective rhetoric".

${ }_{14}$ Phronesis is a characteristic of the well-educated and virtuous man and has the highest value in Isocrates. See Panath. 12.31-32, cf. Pouloakos, Depew 2004: 56-57, passim. Schwarze 1999: 93: "But its meaning is wider: the chief problem of rhetoric does not lie in negotion the alleged distintion between appearance and reality; rather, it lies in generation appearances that will be useful for the community", etc. 
arises when you must be present, rise and take your leave before you become intoxicated; for when the mind is impaired by wine it is like chariots which have lost their drivers [...]. ${ }^{15}$

It is noteworthy that there is a certain link between Isocrates' doctrine and pragmatic theories, as according to modern studies communicative competence is a capability to know when to speak and when to remain silent as well as in relation to what things, whom, when, where and how. ${ }^{16}$ Isocrates gives rules for speaking and remaining silent. Let us mention some Isocratic rules. For example, in his Panegyricus 4.5, he says "for then, and only then, should we cease to speak, when the conditions have come to an end and there is no longer any need to deliberate about them, or when we see that the discussion of them is so complete that there is left to others no room to improve upon what has been said". ${ }^{17}$ Conversely, we should continue speaking when the conjuncture continues being favorable and the problem has not been solved or when nothing is necessary to add.

In his Ad Demonicus 1.41, Isocrates states: "Let there be but two occasions for speech when the subject is one which you thoroughly know and when it is one on which you are compelled to speak. On these occasions alone is speech better than silence; on all others, it is better to be silent than to speak". ${ }^{18}$ The first we could denominate a "rule of authority" and the second a "rule of necessity", as it can occur, for example, when a man is taken before the court or when the slave is taken to be tortured. Even though he does not know, he must speak.

\section{Suitability (to prepon)}

To prepon is another principle of pragmatic competence in Isocrates' rhetoric. In this case, there exists a greater uncertainty than in the others and although the word to prepon is

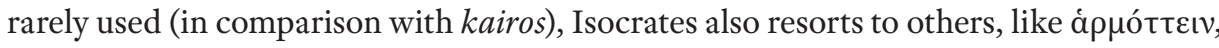
i.e., "to assemble", "to connect", from which ápuovía comes (a word that never appears in Isocrates). Anyway, the concept is important. On this, Kinneavy 2002: 59, writes: "it is not inaccurate to say that kairos, with the related concept of prepon, was a major issue

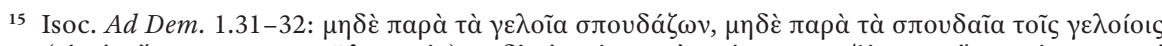

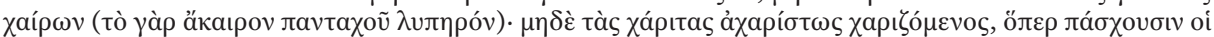

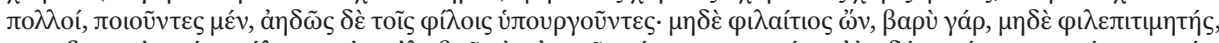

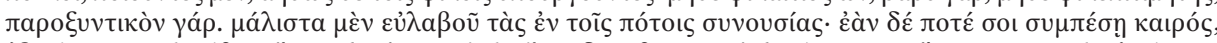

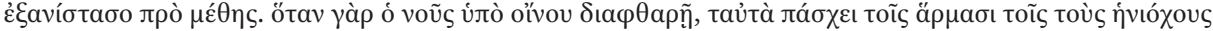

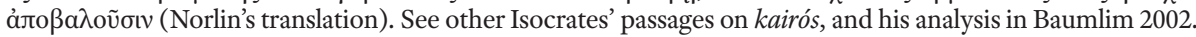

${ }^{16}$ Hymes, apud M. Bertuccelli Pappi 2000: 77.

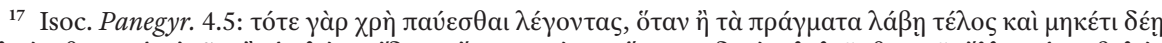

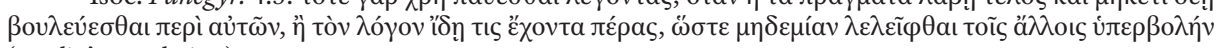
(Norlin's translation).

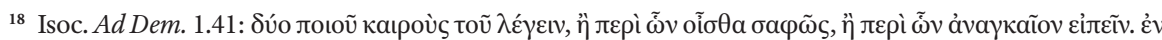

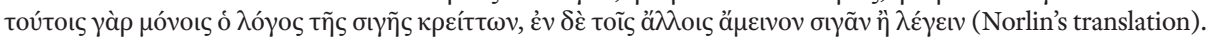


in much of classical rhetoric in antiquity [...]". An example of a use of this concept occurs when the orator advises Nicocles to be urbane and solemn: one adapts well to tyranny; the other to one's companions. ${ }^{19}$

Still, sometimes there seems to be a certain confusion between the opportune moment and suitability. But, even though there are cases in which both terms are identical or complementary, in general there is a differentiation. The criterion of opportunity is based on external conditions. The Persian king waits for the juncture to attack, knowing he is weak. The criterion of suitability, on the other hand, has to do with the actual possibilities that the orator has to adapt himself to, the context, the subject and the addressee. In the first case, in effect, one expects the orator to behave in a certain way. The tyrant must be solemn; an equal one must be urbane. Also, in the speech Ad Demonicus 1.15, Isocrates shows the behavior that a young nobleman like his addressee has to display. Certain words are adapted to young people; others to more mature people ( $c f$. Ad Dem. 1.44). This aspect is very frequent in Isocrates' works.

But Isocrates did not limit the suitability of words or actions to the orator himself, but also employed it to the subject. This happens, for example, in the Antidosis 15.10, where the author affirms: "[...] while some things in my discourse are appropriate [preponta] to be spoken in a court-room, others are out of place amid such controversies, being frank discussions about philosophy and expositions of its power" ${ }^{20}$ This use is particularly important because it has to do with the theory of the genres. A judicial speech is not the same as a political speech. This may seem quite elementary, but without a doubt it is essential within a broader exhibition of the elements for the practice of rhetoric.

It is crucial to point out that behavior often occurs spontaneously, without it being the orator's intention, but sometimes it can also occur consciously, when we behave in a certain way with the intention of persuading. Thus, in his Epistle to the children of Jason 7, Isocrates advises his readers not to be astonished if he repeats things he said before, because, although sometimes he does it without realizing, other times he does it consciously, when it seems to him appropriate [prepon] for the subject. ${ }^{21}$

Isocrates is certainly a traditionalist and supports defined rules of conduct. But he also sees it all from the perspective of effective words and clever actions, because, as he

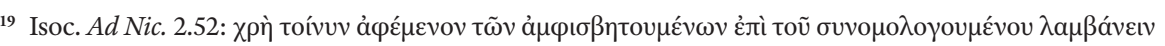

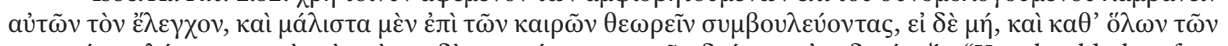

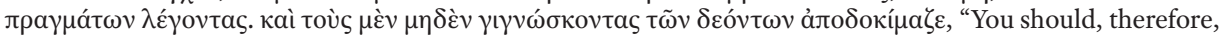
avoid what is in controversy and test men's value in the light of what is generally agreed upon, if possible taking careful note of them when they present their views on particular situations; or, if that is not possible, when they discuss general questions. And when they are altogether lacking in what they ought to know, reject them" (Norlin's translation).

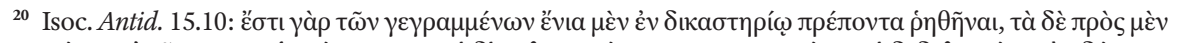

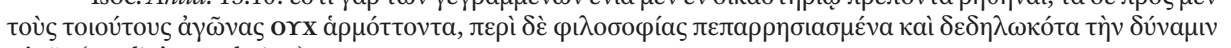
aủt $\tilde{\varsigma}$ (Norlin's translation).

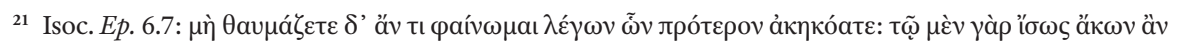

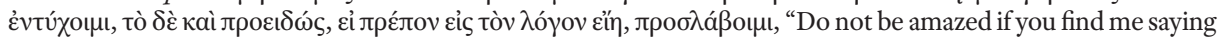


states in the aforementioned passage of his In soph. 13.13: rhetorical effectiveness also depends on the suitability of the words.

\section{Conclusions}

I have limited myself to presenting, in a general way, two elements of Isocrates' rhetorical system, which have to be further studied in greater depth. Nevertheless, one should be careful when studying these aspects. The only aspect that we can understand with certain clarity is the rhetorical competence, the technical elements that take place during the speech generating-process. However, according to Isocrates himself, the most difficult thing is to know how to put discourse into practice; the pragmatic mechanisms that make a speech effective cannot be the object of a discipline. Pragmatic competence is based on practice, on continuous exercises under the direction of a teacher with experience. Only in this way can phrónessis, the practical intelligence of the orator, be acquired. Also, we are unable to modify our natural oratorical capacities. Nevertheless, between a natural oratorical capacity and practical knowledge there is a significant difference, because while it is not possible to influence in the former, it is possible to influence in pragmatic competence. The importance of Isocrates in this field is enormous, because he faces this problem and presents a solution not only to understand how we must speak successfully, but also how we must act successfully in our community. Unfortunately, both terms did not have a special significance in later rhetoric, apart from Cicero, who fused both concepts in the Latin word decorum. But their importance in Isocrates and in ancient Greek rhetoric justifies calling attention to both and considering them when analyzing and performing discourses. 


\section{BIBLIOGRAPHY}

\section{TEXTES AND TRANSLATIONS}

Isocrate, Discours, vol. I-IV, G. Mathieu, E. Brémond (ed.), Paris 1972 [1928-1962].

Isocrates in Three Volumes, vol. 1-3, G. Norlin, L. Van Hook (transl.), Cambridge 1961.

Isocrates I, D. Mirhady, Y. L. Too (transl.), Austin 2000.

Isocrates II, T. L. Papillon (transl.), Austin 2004.

\section{STUdies}

Baumlin, J. S., 2002, “Ciceronian Decorum and the Temporalities of Renaissance Rhetoric”, in: Sipiora, Baum$\lim 2002$, pp. 138-186.

Bertuccelli PAppi, M., 2000, Chè cos'è la Pragmática, Milano.

KinneAvy, J. L., 2002, “Kairos in Classical and Modern Rhetorical Theory”, in: Sipiora, Baumlim 2002, pp. 58-76. Matson, W. I., 1957, “Isocrates the Pragmatist”, The Review of Metaphysics 10, pp. 423-427.

Poulakos, T., DePew, D. (eds.), 2004, Isocrates and Civic Education, Austin.

RAMírez VidAL, G., 2016, La invención de los sofistas, México.

SchiAPPA, E., 1999, The Beginnings of Rhetorical Theory in Classical Greece, New Haven-London.

Schwarze, S., 1999, “Performing Phronesis: The Case of Isocrates' Helen”, Philosophy \& Rhetoric 32, pp. 78-95. Sipiora, P., BAUMlin J. S. (eds.), 2002, Rhetoric and Kairos. Essays in History, Theory and Praxis, Albany.

Sullivan, R. G., 2001, “Eidos/idea in Isocrates”, Philosophy \& Rhetoric 34, pp. 79-92.

Timmerman, D. M., 1998, “Isocrates' Competing Conceptualization of Philosophy”, Philosophy \& Rhetoric 31, pp. $145-159$.

Too, Y. L., 1995, The Rhetoric of Identity in Isocrates, Cambridge.

GERAR DO RAMÍREZ

V I D A L

/ National Autonomous Universty of

México, Mexico /

grvidal18@gmail.com

\section{Pragmatic Rhetorical Principles in Isocrates}

While Isocrates regarded rhetoric not as a rigid discipline, but as a creative and pliable art, it is not possible to standardize art. According to his point of view (Against the sophists 13.13), good speech depends on certain principles: opportunity (kairos); suitability (to prepon) and novelty (kainos). The sophists, according to Isocrates, did not pay attention to these principles, and that was their main mistake. The problem was, however, that it was difficult to teach these principles to the disciples, precisely because rhetoric was a flexible art. Still, although it is not possible to provide fixed rules concerning rhetorical principles, the ancient $r$ hetor provided some useful suggestions in his works which make it possible to reconstruct the nature of these principles.

Isocrates, rhetoric, kairos, to prepon, kainos 
- 